\title{
V5 - LC-MS/MS as a tool for analysis of underivatized glutamic and aspartic amino acids residues from tetanus toxoid
}

Marilza Batista Corrêa ${ }^{1 *}$; Hilton Jorge Nascimento ${ }^{1}$; PatríciaBarbosa Jurgilas ${ }^{1}$; Renata Chagas Bastos ${ }^{1}$; José Godinho da Silva Junior ${ }^{1}$; Maria de Lourdes M. Leal $^{1}$; Ellen Jessouroun ${ }^{1}$; Ivna Alana da Silveira ${ }^{1}$.

\section{1 - Bio-Manguinhos/FIOCRUZ}

\section{Introduction:}

Bio-Manguinhos has developed a meningococcal serogroup $\mathrm{C}$ vaccine based on conjugation of menigococcal polysaccharide (PSC) with monomeric tetanus toxoid (MTT). The conjugation process is based on oxidation of PSC followed by reaction with hydrazine activatedmonomeric tetanus toxoid (MATT). The protein activation reaction occurs selectively in aspartic and glutamic residues. The quantification of these residues in MATT is essential to assure the quality of the produced conjugate. For this aim a sensitive methodology is required since there isn't a single method that deal with modified and non-modified residues. In this report, we showed preliminary data of the underivatized amino acids analysis by LC-MS/MS.

\section{Objective:}

The goal of this work is thedevelopment of a specific and sensitive method based on LC- MS/MS for quantification of underivatized glutamic and aspartic acid released after acidic hydrolyzed MTT.

\section{Methodology:}

Glutamic and aspartic acids standards were dissolved in $0.1 \%$ formic acid solution, and applied by either infusion or autosampler system. The mass spectrometer was operated in positive ion mode. ESI-MS/MS parameters Collision Energy (CE), Entrance Potential (EP) and Declustering Potential (DP) were optimized for each analyte taking into account its precursor ion intensity. CE and DP were tuned considering the complete fragmentation of precursor ion in MS/MS. Glutamic and aspartic acids fragmentation patterns were performed for SRM (Selected Reaction Monitoring) studies. The analytes were chromatographed onto HPLC-RP C-18 (Vydac, 100 x $4.6 \mathrm{~mm}$, particle size $5 \mu \mathrm{m})$ followed by ESI-MS/MS analysis in tuned conditions. The linearity was 
monitored using different concentrations of glutamic acid ranging from 2.0 to $1.0 \mathrm{x} 104 \mathrm{pmol} / \mu \mathrm{L}$. All samples were analyzed in triplicate and the statistical parameters were evaluated.

\section{Results:}

The fragmentation patterns of the precursor ions were compatibles with amino acid cleavages $[\mathrm{M}+\mathrm{H}-\mathrm{H} 2 \mathrm{O}]+;[\mathrm{M}+\mathrm{H}-\mathrm{NH} 3]+;[\mathrm{M}+\mathrm{H}-\mathrm{HCO} 2 \mathrm{H}]+$ and $[\mathrm{M}+\mathrm{H}-\mathrm{CH} 3 \mathrm{CO} 2 \mathrm{H}]+$. In order to perform SRM studies the transitions $148.1^{\oplus} 84.1$ and $134.1^{\oplus} 74.0$ were selected for glutamic and aspartic acids, respectively. The area obtained for the MS/MS peaks selected for glutamic acid was proportional to its concentration. The standard curve was linear in the interval of $2.0-100.0 \mathrm{pmol} / \mu \mathrm{L}(\mathrm{R} 2>0.99$; $\mathrm{SD}<10$; Bias \% < 5).

\section{Conclusion:}

The results so far obtained suggest that LCMS/MS can be used to quantify amino acids targets with accuracy and precision. Subsequent experiments will be carry out with hydrolyzed MTT and its activated form.

Keywords: SRM, amino acids. 